\title{
Far-and Near-Field Optical Second-Harmonic Microscopy of Domain Structures
}

\section{Bozhevolnyi, Sergey I.}

Published in:

Proceedings of the European Quantum Electronics Conference

Publication date:

1998

Document Version

Publisher's PDF, also known as Version of record

Link back to DTU Orbit

Citation (APA):

Bozhevolnyi, S. I. (1998). Far-and Near-Field Optical Second-Harmonic Microscopy of Domain Structures. In Proceedings of the European Quantum Electronics Conference (pp. 97-97). IEEE.

\section{General rights}

Copyright and moral rights for the publications made accessible in the public portal are retained by the authors and/or other copyright owners and it is a condition of accessing publications that users recognise and abide by the legal requirements associated with these rights.

- Users may download and print one copy of any publication from the public portal for the purpose of private study or research.

- You may not further distribute the material or use it for any profit-making activity or commercial gain

- You may freely distribute the URL identifying the publication in the public portal

If you believe that this document breaches copyright please contact us providing details, and we will remove access to the work immediately and investigate your claim. 


\subsection{OTul7}

FAR-AND NEAR-FIELD OPTICAL SECOND-HARMONIC MICROSCOPY OF DOMAN STRUCTURES

Mergey I. Bozhevolnyj

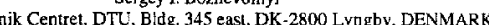
Fax:(+45) 45887762; Tel: (+45) 45255763; E-mail: sbo@mic.dtu.dk

Local probing of second-order susceptibilities with a scanning near-field optical microscope and a conventional far-field microscope arrangement is demonstrated for domain structures in periodically poled $\mathrm{LiNbO}_{3}$ crystal and a multilayer Langmuir-Blodgett film of 2-docosylamino5-niropy (DCAN). ( wavelengths is deced while simultaneously recording surface topography. The experimenta cep comed mode-lock TTis duration $\tau \sim 200$ is) is coupled into a single-mode fiber terminated with a sharp etched tip. FH radited from a sample) and $\mathrm{SH}$ gented in sample are collected by a microobjective and detected with a phorodiode and a photomultiplie (comected wh a phe by a micor at a cont a disaphe Iinage of the salne that is colct with CCD $C$ Th CCD a mis is colve (NA. $=0.4$ ) storate the images.

$$
\text { Domain }
$$

Domain walls in a periodically poled ( $z$-cut) $\mathrm{LiNbO}_{3}$ crystal have been observed on near-field SH-images in the form of bright lines of $\sim 500 \mathrm{~nm}$ in width for the SH polarization being perpendicular to the dornain walls. Similar images have been also obtained with the farOrigin of the the scaning of

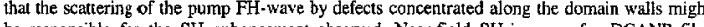
ences a fill exheir bed very brght submicrometer sized spols wilh signal enhancement of up to 10 times. Their brightress is found dependent on the polarizaton of the pump indicating that the domain observed onented differently but predominanty in the dipping direction. The spatial resolution

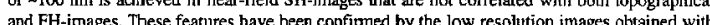
and $\mathrm{FH}$-images. These forld

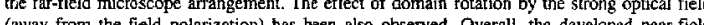

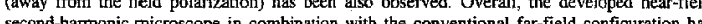
been found useful to quickly idenify and survey suface structures showing nolinear op cent lound useful to quickly identify and survey surface structures showing nonlinear optical very sencitive to the symmetry and interace propertices and therefore this tochnique con to be a wealth of addition information (not avalable from linear imaging) on the namoner
17.30 QTul8

NONLINEAR PROPAGATION

OF ELECTROMAGNETIC RADIATION IN YACUUM

N.N.Rosanov

Institute for Laser Physics, Research Centre "S.I.Vavilov State Optical Institute*

Birzhevaya liniya 12, St. Petersburg, 199034 RUSS1A

Telephone: 78122181093 Fax: 78122185891

E-mail: rosanov@ilph.spb.su

There are two mechanisms of a pure vacuum optical nonlinearity with respect to high-power radiation. First, it is a quantum-electrodynamical phenomenon of electron-positron yacuum polarization. Second, it is a classical (Einsteinian) phenomenon of gravitation induced by electromagnetic radiation [1]. Athough these phenomena are locally weak, their effect can be accumulated for a long distance of tadiation propagation.

In the present paper, a theory of propagation of high-powet electromagnetic radiation beams and pulses with small (diffractive) angular divergence in such a vacuum is developed. Importan point of the theory is use of developed in monlinear optics method of parabolic (quasioptical) equation. For the quantum-electrodynamical mechanism, the Heisenberg-Euler theory is modified to take into account vacuum dispersion which is important for ultrashort radiation pulses. Under approximation of slowly varying envelope a parabolic equation is deduced th describes radiation diffraction, spatio-temporal dispersion, and vacuum nonlinearity. I show existence of dark optical solitons in the vacuum [2]. These phenomena can be demonstrated in high-power laser facilities of existent leve.

For the classical gravitational mechanism, additionally to the Maxwell's equations, the lincarized Einstein's equations of gravitation are involved (the first approximation of perturbation theory which is valid for weak gravitational fields), and the parabolic equation is deduced. Contrary to the previous case, nonlinear effective electucal permittivity is highly nonlocal here. For approximation of quadratically inhomogeneous effective electrical permittivity, solution of the parabolic equation is received which describes nonlinear focusing and defocusing of a weak probe electromagnetic radiation on the background of a strong radiation beam/pulse. Estimation show that gravitational mechanism of a pure vacuum nonlinearity can be important for extrem cosmological events.

\section{References}

1.R.C. Tolman. Relativity, Thermodynamics and Cosmology. Oxford. Clarendon Press. 1969 2. N.N.Rosanov. On self-action of high-power electromagnetic radiation in electron-positron vacuum. JETP, 113(2) (1998) 